\title{
Analysis of Household Lighting Fuel Choice in Rwanda: Multinomial Logit Model
}

\author{
Niyonshuti Emmanuel \\ African Centre of Excellence in Energy for Sustainable Development, department of Energy Economics, University of Rwanda Kigali, \\ Kigali, Rwanda \\ Email address: \\ niyency@yahoo.fr

\section{To cite this article:} \\ Niyonshuti Emmanuel. Analysis of Household Lighting Fuel Choice in Rwanda: Multinomial Logit Model. American Journal of Modern \\ Energy. Vol. 7, No. 4, 2021, pp. 69-74. doi: 10.11648/j.ajme.20210704.14
}

Received: March 18, 2021; Accepted: March 29, 2021; Published: August 31, 2021

\begin{abstract}
The overdependence on using traditional fuels for lighting purposes is closely associated to indoor air pollution, environmental humiliation and high opportunity cost for women and children and consequently affect household well-being, the social economic welfare of deprived population in developing nations to be improved there should consider the adoption and usage of modern lighting services as very important. This paper identifies the determining control factors that influence the fuel energy choice for lighting purposes in Rwanda by applying the Multinomial logit regression to the national representative survey at household level data. The study revealed that the households with higher income are adopting to use the cleaner and modern fuel energy source, confirming the hypothesis for energy ladder. Not only household income exerting impact on the fuel energy choice for lighting, the other fuel choices significant determining variables in Rwanda are: number of the rooms occupied by household, type of dwelling for household, age of the household head, whether the household head has formal education level, the household size, type of the habitant for the household and the location of the household. This paper suggests deployment and utilization of solar potentiality for supplying the cleaner and modern fuel energy for lighting purposes in the remote area of Rwanda.
\end{abstract}

Keywords: Rwanda, Energy Choice, Lighting, Multinomial Logit Regression

\section{Introduction}

The socio-economic welfare of underprivileged population in developing country to be improved there should be taking consideration of modern lighting services as very crucial. The people without modern clean lighting fuel accessibility automatically tend to use the traditional, inefficient and hazardous lighting fuel energy like oil lamp, kerosene and firewood for meeting their lighting demands [14]. Hence this research paper aims to investigate the driving forces that influence the transition to modern from traditional fuel energy for lighting purposes. The energy is considered as a basic need and there was a correlation between absolute poverty with not adopting to use modern energy [27]. Currently, the sub-Saharan Africa region and other developing nations face limited accessibility to inexpensive and clean modern fuel energy sources. It is assessed that 2.5 billion of individuals rely on the traditional biomass which are solid fuels such as firewood and crop residues for cooking and heating purposes which are related with circuitous adverse healthiness impacts [5]. The forecasted data shows that the population without access to clean and modern fuels and rely on the traditional biomass the number is likely to rise to 2.7 billion of the vulnerable population by 2030 resulting to depleting the forest and degradation of the environment that might be unavoidable if there is no timely and well formulated policy measures [11]. Due to this critical issue, the advancement in clean and modern fuel energy technologies is crucial for easy transition of fuel energy in order to improve the accessibility and adaptation to use the clean, modern energy services to lessen the energy dispossession [19]. Nonetheless, the prosperous uptake of clean and modern fuel energy technologies is largely associated to the consumer preferences and demand typically from the household level.

Other than household income, control factors like formal education of household head, age of household head, household size, family proportion in terms of children, old 
members and female member, availability, accessibility may influence the fuel energy choices [24]. The distance travel from market places, the existence of infrastructures and channel for energy distribution also have an impact on fuel energy choice, the fuel energy supply reliability and higher installation cost are also significant control determinants of fuel energy choices [13]. The governmental policy that stimulate or disheartening the usage of particular type of energy may also influence the fuel energy choices [10].

There are previous studies like [7] which not only use the discrete choice analysis but also investigating the fuel energy transition at household level following the theoretical approach which is energy ladder hypothesis and some follow the energy stacking hypothesis, therefore this paper utilized the cross-sectional data which encompassed by EICV3 2010/2011, EICV4 2013/2014 with the latest EICV5 2016/2017 data set that detect the socio-economic and demographic information at household level to investigate the lighting fuel energy choices for Rwandan households in the context of the urbanization.

This study not only contributing to the expansion of the literature and then scope of the urban context research gap that was left by [16] who investigate the fuel energy choices only in Kigali city, but also provide the full information with seizure of time in order to examine other fixed effects influencing the fuel choices in the context of urbanization about lighting fuel energy choice in Rwandan households from 2010 up to 2018 by giving complements to [7] who only centered on the EICV4 2013/2014 data set which doesn't capture time for examining other fixed effects that may impact the fuel energy choices at household level using a discrete choice analysis with their findings indicates that household wealth levels and other regional differences are likely to influence choice probability for using cleaner energy sources. The country has experienced rapid urban growth that is accompanied by demographic growth and migration to urban areas and greater urbanization is explicit in Rwanda's plans for becoming a middle-income country by 2020 (World Bank, 2018a). The Rwandans living in cities and towns are predicted to double from current estimation of 17 percent to 35 percent by $2024[8,29]$.

This study is opportune and related considering the quick country's urban development. This development may fortify an enormous surge in the in household fuel energy demand coupled with vibrant urban lifestyles, which has well formulated policy implications. The urban households have an included advantage of revelation towards an assortment of clean and modern commercial fuel energy choices such as solar energy to upgraded accessibility and availability that may further persuade switching between fuel energies [6]. Which indicates that the household subdivision can propose a striking market and viewpoint for diffusion of commercial modern and cleaner fuel energy technologies [7]. However, there are many driving forces exerting influence on the household fuel energy choices and differ depending on the preferences, context, transitional level by household and the availability of the fuel energy sources to the households centered on the energy ladder cross section [23]. The reasons for households to use multiple fuel energies in developing nations are ascribed not only to economic control factors like household income but also to non-economic driving factors to meet fuel energy household demand.

In the context of Rwanda, the main sources of fuel energy for lighting are: firewood, electricity, oil lamp, candle \& lantern, solar panels and batteries as shown in table 1. While batteries are the main source of fuel energy for lighting in rural households while electricity is the main for urban households in Rwanda, it is very crucial to note that in rural region in Rwanda, around 5.35 percent population rely on oil lamp and 6.31 percent for firewood. Thus, there is a necessity to investigate as to what determine Rwandan households' fuel energy choices for lighting which will help the well and improve policy formulation towards the fuel transition from traditional to cleaner and modern fuel energy. As of now, the literature on this area focusing on the whole country Rwanda is narrow. Subsequently, this study ascertains the determining control factors of fuel energy choices for lighting at household level in Rwanda.

\section{Methodology and Data}

The study used the pooled cross-sectional survey data from integrated household living conditions surveys (EICVS) data, carried out by National Institute of Statistics of Rwanda (NISR) three waves $(2010 / 2011 ; 2013 / 2014$ and 2016/2017), This survey was a broadly agent test for statistics intended to give data on different parts of the households in Rwanda. The reviews gathered data from three waves-based household measurably intended to be delegated at both public, rural, urban and provincial levels [21].

The current study uses the multinomial logit mode to identify the driving forces of household's choice for lighting fuel energy in line with the most common methodology applied in the context of diverse countries. Some of the studies are: Maheshwar G. and Goswami B. (2017) for energy choice in Nepal; Yonas, Abebe, Gunnar and Mekonnen (2015) in modelling the cooking fuel energy choice in urban Ethiopia; Abdalla M. El-Habil (2012) in Palestine and Rafael da Silveira Moreira with Vanessa de Lima Silva (2019) in Brazil. In this multinomial logit model, out of $\mathrm{j}^{\text {th }}(\mathrm{j}=1,2,3 \ldots . \mathrm{k})$ energy options categories of the dependent variable, one category was considered as a reference category and the probability of adopting to use the other fuel energy categories was compared to the probability of choosing the reference fuel energy category.

The multinomial logit regression model used in this study was shown below:

$$
\log o d d s=\log \left(\left(\frac{P(Y=j \mid x)}{P(Y=J \mid x)}\right)\right)=\delta_{0}+\sum \beta_{i k} X_{i k}
$$

Where $X_{i k}$ is the set of all explanatory variables, $\beta_{i k}$ are the corresponding parameters of interest to be estimated, $\delta_{0}$ is the intercept of the regression model and $\mathrm{Y}$ is the 
categorical dependent variables of lighting energy options.

The set of explanatory variables included in the regression model $X_{i k}$ are: household total income, age of the household head, the number of the rooms occupied by the household, whether the household head has the formal education level (dummy), type of dwelling occupied by the household, type of habitant for the household, household size which entails the number of household members, household location whether is located in urban or rural region, homeownership which implies whether the household live in their own house or rent house and the type of the marriage for household head (dummy) whether the head is polygamous or not.

Here the exponential of the predicted $\log$ odds for $j=2 \ldots . . k$ gives the respective probabilities of adopting to use the corresponding fuel energy for lighting purposes.by deducting the summation of probabilities for $\mathrm{j}=2 \ldots \mathrm{m}$ from one, the probability of the reference energy category can be obtained.
In this study, the dependent variable is a discrete category of the lighting fuel energy options like electricity, firewood, solar panels, battery, candle and lantern, as is shown in table 1. Here the base fuel energy category is lantern.

For this regression model there are six log odds and will be compared each to the reference base fuel energy category (solar panel). It is assumed that the log odd is a linear function of the predictor. The ratio of the log odds shows how many time more likely a particular fuel energy category is being adopted to be used relative the reference fuel category.

\section{Results and Analysis}

Here we first represent the results from descriptive statistics analysis and thereafter we describe the results from multinomial logit regression model

\subsection{Descriptive Statistics for Households' Characteristics and Lighting Fuels Choices}

Table 1. Summary of statistics of explanatory control variables used in $M N L$.

\begin{tabular}{|c|c|c|}
\hline Explanatory control variables & Mean & Std. Dev. \\
\hline Household location & 0.16 & 0.367 \\
\hline Type of habitant for household & 2.324 & 1.644 \\
\hline Age of household head & 45.103 & 15.824 \\
\hline Formal education for household head & 0.391 & 0.488 \\
\hline Type of marriage for household head & 0.061 & 0.239 \\
\hline Number of Household members & 4.59 & 2.14 \\
\hline Household home ownership (Own/Rent) & 0.812 & 0.391 \\
\hline Household Total income & 12.485 & 1.627 \\
\hline Type of dwelling for household & 0.915 & 0.278 \\
\hline Number of rooms occupied by household & 3.624 & 1.205 \\
\hline
\end{tabular}

Source: author's computations using EICVs (2010/12; 2013/14 and 2016/17)

From the table 1 above reports for the sample used in this study, only household living in the urban area are averaged at 16 percent as the household location was taken as dummy and urban location was taken as 1 and the age of household was averaged at 45 years while household head with formal basic education were averaged at 39 percent as formal education was considered as dummy and if the household with formal education was taken as 1 . The household heads who are polygamous were averaged at 6 percent since polygamous was taken as dummy and polygamous household was considered as 1 while the household size was averaged at 4 household members. The households living in their own houses were averaged at 81 percent as homeownership was considered as dummy and household owning he house was taken as 1 and the average number of rooms occupied by the household was averaged at 3 rooms.

Table 2. Fuel energy sources for lighting in Rwanda (in \%).

\begin{tabular}{|c|c|c|c|c|c|c|}
\hline \multirow{2}{*}{ Primary source of lighting fuel } & \multicolumn{3}{|l|}{ Household location } & \multicolumn{3}{|c|}{ year of survey } \\
\hline & Rural $(\mathrm{N}=\mathbf{3 6 , 3 5 7})$ & Urban $(N=6,950)$ & Total & 2010 & 2013 & 2016 \\
\hline electricity & 8.89 & 64.68 & 17.84 & 10.57 & 17.99 & 24.83 \\
\hline oil lamp \& gas & 5.38 & 5.17 & 5.35 & 9.60 & 5.08 & 1.43 \\
\hline firewood & 7.33 & 0.98 & 6.31 & 8.87 & 6.06 & 4.05 \\
\hline Candle \& lantern & 24.29 & 18.92 & 23.43 & 40.81 & 20.62 & 9.14 \\
\hline solar panel & 3.77 & 0.43 & 3.23 & 0.33 & 1.78 & 7.52 \\
\hline Batteries \& others & 50.35 & 9.83 & 43.84 & 29.82 & 48.47 & 53.02 \\
\hline
\end{tabular}

Source: author's computations using EICVs (2010/12; 2013/14 and 2016/17) 


\subsection{Results from Estimations of Multinomial Logit Regression Model}

Table 3. Estimations of Factors influencing the household lighting fuel choices.

\begin{tabular}{llllll}
\hline VARIABLES & Electricity & Oil lamp\&gas & Firewood & Candle \&lantern & Battery\&others \\
\hline Household total income & $0.0680^{* * *}$ & $-0.694^{* * *}$ & $-1.000^{* * *}$ & $-0.812^{* * *}$ & $-0.644^{* * *}$ \\
& $(0.0243)$ & $(0.0272)$ & $(0.0273)$ & $(0.024)$ & $(0.0233)$ \\
Household location & $3.133^{* * *}$ & $2.085^{* * *}$ & -0.0497 & $1.816^{* * *}$ & $0.557^{* * *}$ \\
& $(0.191)$ & $(0.199)$ & $(0.229)$ & $(0.192)$ & $(0.193)$ \\
Type of habitant for household & $0.271^{* * *}$ & $-0.185^{* * *}$ & $-0.243^{* * *}$ & $0.155^{* * *}$ & $0.107^{* * *}$ \\
& $(0.0259)$ & $(0.0286)$ & $(0.0291)$ & $(0.0257)$ & $(0.0251)$ \\
Age of household head & $-0.00583^{* *}$ & $0.00718^{* * *}$ & $0.0341^{* * *}$ & $0.0105^{* * *}$ & $0.00570^{* * *}$ \\
& $(0.00227)$ & $(0.00245)$ & $(0.00231)$ & $(0.00208)$ & $(0.00201)$ \\
Formal education for HH Head & $0.427^{* * *}$ & $-1.040^{* * *}$ & -0.0973 & $-0.848^{* * *}$ & $0.134^{* *}$ \\
& $(0.068)$ & $(0.0749)$ & $(0.0771)$ & $(0.0645)$ & $(0.0627)$ \\
Polygamous for household head & $0.769^{* * *}$ & $1.283^{* * *}$ & $1.439^{* * *}$ & $1.321^{* * *}$ & $1.088^{* * *}$ \\
& $(0.235)$ & $(0.237)$ & $(0.235)$ & $(0.226)$ & $(0.225)$ \\
Household size & $-0.0417^{* * *}$ & -0.00888 & $-0.0584^{* * *}$ & $-0.0286^{*}$ & $-0.0410^{* * *}$ \\
& $(0.0156)$ & $(0.0172)$ & $(0.0175)$ & $(0.0147)$ & $(0.0142)$ \\
Household home ownership & $1.375^{* * *}$ & $-0.633^{* * *}$ & $-0.670^{* * *}$ & $-0.766^{* * *}$ & $-0.454^{* * *}$ \\
& $(0.123)$ & $(0.135)$ & $(0.134)$ & $(0.122)$ & $(0.12)$ \\
Type of dwelling for household & $1.206^{* * *}$ & $-0.432^{* *}$ & -0.114 & $-0.391^{* *}$ & -0.0468 \\
& $(0.176)$ & $(0.195)$ & $(0.204)$ & $(0.178)$ & $(0.176)$ \\
Number of rooms occupied & $0.103^{* * *}$ & $-0.130^{* * *}$ & $-0.529^{* * *}$ & $-0.127^{* * *}$ & $-0.238^{* * *}$ \\
& $(0.0258)$ & $(0.0279)$ & $(0.0312)$ & $(0.0253)$ & $(0.0245)$ \\
Constant & $1.612^{* * *}$ & $8.597^{* * *}$ & $13.61^{* * *}$ & $12.72^{* * *}$ & $11.90^{* * *}$ \\
Observations & $(0.382)$ & $(0.419)$ & $(0.421)$ & $(0.375)$ & $(0.368)$ \\
Standard errors in parentheses $* * * \mathrm{p}<0.01, * * \mathrm{p}<0.05, * \mathrm{p}<0.1$ & 43,111 & 43,111 & 43,111 & 43,111
\end{tabular}

Source: author's computations using EICVs (2010/12; 2013/14 and 2016/17), Pseudo R-square=0.1880; Log likelihood=-50769.91; LR chi2 (50)=23515.51; Prob $>$ chi $2=0.0000$. Standard errors in parentheses

From the above table 3 reports that when the household income is increased by one unit this leads to the 6.8 percentage that households are significantly at $\mathrm{p}<0.01$ more likely to use the electricity energy for lighting relative to solar panel while this is associated with the 69.4 percent, 81.2 percent and 64.4 percent that households are significantly at $\mathrm{p}<0.01$ less likely to use oil lamp, candle\&lantern and batteries respectively relative to solar panel for lighting purposes and since the solar panel is considered as cleaner source of energy for lighting given available options and hence the conformity of with the energy ladder hypothesis which accord the findings from [20] carried out the study in Uganda and the findings from [2].

Compared to the rural households the households living in the urban areas are significantly at $p<0.01$ more likely to use electricity relative to the solar panel for lighting purposes compared to the usage of the solar panel due to fuel energy accessibility and affordability and commonly solar panel are used for remote areas electrification means while the urban households are 4.9 percent less likely to use the firewood fuel for lighting purposes and surprisingly the households living in urban areas are significantly at $p<0.01,55.7$ percent more likely to use batteries, piles relative to solar panel for lighting purposes which accords the findings from the studies carried out by $[25,15]$ in Kenya.

However, compared to the households living in unplanned clustered rural areas and isolated rural areas, households living in umudugudu and modern planed areas are 27.1 percent significantly at $\mathrm{p}<0.01$ more likely to adopt using electricity relative to solar panel for lighting purposes while the households living in the umudugudu and modern planned areas are 18.5 percent and 24.3 percent less likely to adopt using oil lamp and firewood relative to solar panel respectively for lighting purposes and those are all significantly at $\mathrm{p}<0.01$. More interestingly, when the age of household head is increased by one year additional this leads to 0.5 percent significantly at $\mathrm{p}<0.01$ less likely to adopt using electricity relative to solar panel for lighting purposes while this is associated with 3.4 percent and 1 percent more likelihood for the household to use firewood and candle\&lantern respectively relative to solar panel for lighting purposes and these are significant at $p<0.01$ that accords the findings from the study carried out by [12] in Bangladesh.

The household headed by member with formal basic education compare to household head without formal education, the household is 42.7 percent and 13.4 percent more likely to adopt using electricity and batteries, piles respectively compared to the solar panel while household headed by member with formal education is less likely to use the oil lamp, firewood and candle \&lantern relative solar panel for lighting purposes which accord the findings from [17]. However, when the type of the marriage for household head is polygamous is also a significant determinant of fuel energy choice, this is associated with more likelihood of adopting to use electricity, firewood, oil lamp, candle\&lantern and batteries, piles relative to solar panel for lighting purposes and all significant at $\mathrm{p}<0.01$ since polygamous household head are easily adopting to choose other lighting fuel energy sources relative to solar panel due to associated installation and maintenance costs and 
this accords the findings from the study carried out by [22] in Cameroon.

When the household size is increased by one member additional there is less likelihood of adopting to use electricity, oil lamp, firewood, candle\&lantern and batteries for household relative to the solar panel, not surprisingly when the household live in their own house this leads to more likely to use electricity relative to solar panels and less likely to adopt using oil lamp, firewood, candle\&lantern and batteries for lighting relative to solar panel and this accords the findings from the study conducted by both [1,9]. More interestingly when the household live in the multiple and stories houses compared to single houses there is a significant at $\mathrm{p}<0.01$ more likelihood to adopt using electricity for lighting relative to solar panel due to associated installation and maintenance cost for roof top solar panels and easy accessibility resulted from developed infrastructure while households living in multiple and stories houses are significant at $\mathrm{p}<0.05$ less likely to use oil lamp and candle \&lantern relative to solar panel for lighting purposes which accords the findings from the study carried out by [18] in Ethiopia. Interestingly, when the number of rooms occupied by the household is increased by one room this leads a significant at $\mathrm{p}<0.01$ more likelihood of adopting to use electricity relative to solar panel for lighting purposes while one room additional is associate with significant at $\mathrm{p}<0.01$ less likelihood of oil lamp, firewood, candle \&lantern and batteries for lighting relative to solar panel since increased number of rooms leads to increase in fuel energy demand hence increased cost of using these fuel energy sources compared to solar panel which accords the findings from study carried out by [28] in Malawi.

\section{Conclusion and Policy Recommendations}

The significance of lighting is frequently followed by other energy demands, such as cooking. Nevertheless, clean and modern lighting services are essential for improving the socio-economic wellbeing of deprived people in developing countries, so it is important to have an advanced understanding of driving control factors which influence household's lighting fuel energy choice trough advancement of the fuel energy transition. Using nationally representative survey EICV, 2010-11, 2013-14 and 2016-17 data, and the study has described the determinants of lighting fuel energy choices in Rwanda using Multinomial logit model. The findings of the study accords the hypothesis of the energy ladder. Other determinant control variables lighting fuel energy choices than income are household head age, whether household head has formal basic education, household size, type of habitant for the household, type of dwelling for the household, number of the rooms occupied by the household, type of the marriage for the household head, home ownership for the household and household location. Even though, this study was carried out in Rwanda, but many other developing countries in which households tend to rely on traditional lighting fuel energy, so the policy drawn here will be more important for these countries.

The major finding of the econometric analysis is that as the household income increase, the household tend more likely to use the electricity for the lighting purposes relative to solar panels. Electricity is in fact the topmost lighting fuel energy source in urban area while batteries are the main source of lighting fuel in rural of Rwanda. Meanwhile, it is very interesting to note that households that are still relying on the candle and lantern in urban area are approximately 18.92 percent. National grid connection to the whole country for rising up the percentage of the electrified households is challenging in Rwanda due to transmission and distribution cost and geographical terrain in remote areas, so solar energy was seen as a long-term cost effective solution for this challenge [4, 3]. However only 3.77 percent of the rural households in Rwanda use solar energy, in fact, when the household income increase, households tend to use electricity relative to solar panel resulting from the quantity demand viability for the end consumer.

Currently, on-grid installed solar energy is $12.08 \mathrm{MW}$ with energy potentiality of about $5.5 \mathrm{Kwh} / \mathrm{m}^{2} /$ day and around 189,069 households are accessing electricity through off-grid solution, mostly solar home systems [26]. However, there is still a scope of promoting solar energy plants in many areas through improving rural electrification with renewable energy. The government may consider subsidies scheme through financial support for setting up small scaled solar plant and even the household solar systems. However, currently the government of Rwanda through Rwanda development board program called "Cana Uhendukiwe" is financially supporting the households especially in establishment of small scale and household solar home systems ownership to overcome the lighting fuel energy transition challenge in the whole country.

\section{References}

[1] Adeyemi, P. A. and Adereleye, A. (2016). Determinants of household choice of cooking energy in Ondo state, Nigeria. Economics and Sustainable developement, 7 (9), 131-142.

[2] Ado, A., Darazo, I. R. and Babayo, M. A. (2016). Determinants of fuel stacking behaviour among households in Bauchi Metropilis. the business and mamangement review 7: 3 .

[3] Bhandari, R. and Stadler, I. (2011). Electrification using solar photovoltaics in Nepal,. Applied Energy, 88 (2), 458-465.

[4] Bhattacharrya, S. C. (2006). Energy access problem of the poor in India: rural electrification remedy? Energy Policy 34 (18), 3387-3397.

[5] Buba, A., Abdu, M., Adamu, I., Jibir, A. and Usman, Y. I. (2017). Socio-economic determinants of household fuel consumption in Nigeria. international journal of research Granthaalayah 5, 348-360.

[6] Farsi, M. and Filippini, M. (2007). fuel choices in urban indian households. environment and development economics 


\section{$12,757-774$.}

[7] Fydess K. M. Umaru G. W., Etienne N. (2020). Determinants of home lighting fuel choices in Rwanda: A Discrete choice analysis. journal of energy and power engineering 14, 131142.

[8] Gubic, and Baloi, O. (2019). public open space initiatives for healthier cities in Rwanda. Vol 5 No 2 (2020): SPECIAL ISSUE: Public Health and Well-being in Public Open Spaces through Climate Responsive Urban Planning and Design.

[9] Hertberg, R. (2004). Fuel switchhing: evidence from eight developing countries. Enerrgy Economics, 26 (5), 869-887.

[10] Hertberg, R. (2005). factors determing household fuel choice in Gwatemala. environment and development economics 10, 337-61.

[11] International Energy Agency. (2006). world energy outlook. paris.

[12] Komatsu, S., Kaneko, S., Shrestha, R. M. and Ghosh, P. P. (2011). Nonincome factors behind the purchase decisions of solar home systems in rural Bangladesh. energy sustainability developement 15, 284-92.

[13] Koswari, R. and Zerriffi, H. (2011). three dimensional energy profile: a coneptual framework for assessing household energy use. Energy Policy, 39 (12), 7505-7517.

[14] Lam, N. L., Smith, K. R., Gauthier, A., and Bates, M. N.. (2012). Kerosene: a review of household uses and their hazards in low-and middle income countries. J. Toxicol. Environ. Health B Crit. Rev. 15,, 396-432.

[15] Lay, J., Ondraczek, J., and Stoever, J. (2013). Renewables in enrrgy transition: evidence on solar home systems and lighting fuel choice in Kenya. Energy Economics 40, 350-9.

[16] Marathe, S. D., and Eltrp, L. (2017). Domestic energy consumption paterns in kigali, Rwanda- how disparate are they in view of urbanisation? international conference on the domestic use of energy (DUE).

[17] Mbaka, C. K., Gikonyo, J. and Kisaka, O. M. (2019). Households' energy prefernce and consumption intensity in Kenya. energy sustainability and society 9:, 20.
[18] Mekonnen, A., and Kohlin, G. (2009). Determinants of households fuel choicein Major cities in Ethiopia. working papers in economics (399): 1403-65.

[19] Morrisey, J. (2017). The energy challenge in sub-sharan africa: a guide for advocates and policy makers: part 2: addressing energy poverty. Oxfam Research Background Series.

[20] Mwaura, F., Okoboi, G., and Ahaibwe, G. (2014). determinants of household's choice of cooking energy in uganda. economic policy research center (EPRC) Kampala, Uganda.

[21] National Institute of Statistics of Rwanda (NISR). (2018). Rwanda Poverty Profile Report. Kigali, Rwanda: National Institute of Statistics of Rwanda (NISR).

[22] Nlom, J. H. and Karimov, A. A. (2015). Modeling fuel choice among households in northern Cameroon. sustainability 7: 9989-99.

[23] Pachauri, S. and Jiang, L. W. (2008). the household energy transition in indian and china. Energy Policy 36, 4022-35.

[24] Rahut, D. B., Das, S., Groote, H. D. and Behera, B. (2014). Determinants of household energy use in Bhutan. Energy, 69, 661-672.

[25] Rao, M. N. and Reddy, B. S. (2007). Variations in energy use by Indian households: an analysis of micro-level data,. Energy, 32 (2), 143-153.

[26] Rwanda Development Board. (2020). Renewable Energy situation. Kigali, Rwanda: Rwanda Development Board.

[27] Sher, F., Abbas, A., and Awan, R. u. (2014). an investigation of multidimensional energy poverty in Pakistan; A province level analysis. international journal of energy economics and policy 4, 65-75.

[28] Tchereni, B. H. M. (2013). A Microeconomics analysis of energy choice Behiour in South Lunzu Township, Malawi. Mediterranean journal of social sciences.

[29] Tull, K. (2019). Links between urbanization and employment in Rwanda. Brighton, UK: K4D Helpdesk report 659 Institute of Development Studies. 